\title{
Mechanisms regulating the transport of acetic acid in Saccharomyces cerevisiae
}

\author{
Margarida Casal, Helena Cardoso and Cecília Leão
}

Author for correspondence: Cecilia Leão. Tel: +35153 604310. Fax: +35153604319.

Department of Biology, University of Minho, 4719 Braga Codex, Portugal

\begin{abstract}
Cells of the yeast Saccharomyces cerevisiae IGC $\mathbf{4 0 7 2}$ grown in medium with acetic acid produced a mediated transport system for acetic acid that behaved as an electroneutral proton symport for the anionic form of the acid. The system could transport propionate and formate but not lactate and pyruvate. Uptake of labelled lactic acid was negligible, no mediated transport system activity for this acid being found. The acetate transporter was also found in cells grown in lactic acid or ethanol media, suggesting that the carrier did not require the presence of an external inducer. When cells were grown in lactic acid medium, uptake of labelled acetic acid, at pH 5.0, was biphasic and consistent with the presence of two distinct transport modes for the acid. One of these components corresponded to the acetate/proton symport, and the higher affinity system corresponded to a more general monocarboxylate carrier that could also transport lactate, pyruvate and propionate. Both systems were subject to repression by glucose, fructose, sucrose, maltose or galactose. In glucose-repressed cells, the undissociated form of the acids appeared to be the only one that could cross the plasma membrane, a diffusion mechanism being involved in the acid uptake. Under these growth conditions and when the extracellular pH was lower than that of the cytosol, accumulation of the acid could also be observed, it being a function of the $\Delta \mathbf{p H}$.
\end{abstract}

Keywords: Saccharomyces cerevisiae, yeast, membrane transport, acetate

\section{INTRODUCTION}

Several yeast species contain strains that display the ability to use acetic acid and other weak monocarboxylic acids when added to the culture medium as the only carbon and energy sources (Barnett et al., 1990). Some of these strains have been thoroughly investigated with regard to the transport of the acids across the plasma membrane, the first step of their metabolism. In Candida utilis and Torulaspora delbrueckii, proton symports have been reported for the transport of monocarboxylates (Eddy \& Hopkins, 1985; Leão \& van Uden, 1986; Casal \& Leão, 1995), while in Kluyveromyces marxianus such substrates are transported by a specific uniport system (Fonseca et al., 1991). In Saccharomyces cerevisiae, it is well-established that the utilization of acetic acid as the only carbon and energy source implies the activity of the anaplerotic glyoxylate cycle and the gluconeogenesis pathways, both of which

Abbreviation: CCCP, carbonyl cyanide $m$-chlorophenylhydrazone. are regulated by glucose repression (Gancedo \& Serrano, 1989). These results account for the inability of $S$. cerevisiae to utilize acetic acid in the presence of glucose and therefore the negative effects often attributed to that acid on the yeast metabolic activity, as occurs during grapemust fermentation. Meanwhile, the mechanisms which account for effective uptake of acetate are still unclear, except for the fact that it is recognized as a substrate for the common monocarboxylate/proton symport described in lactic-acid-grown cells of strain S. cerevisiae IGC 4072 (Cássio et al., 1987). This, more recently, has been described as dependent not only on the presence of an inducer in the medium, but also on some internal metabolite derived from the acid metabolism (Casal et al., 1995).

The purpose of our work was to study the transport of acetic acid in S. cerevisiae IGC 4072 in more depth. Evidence is presented that this yeast exhibited significant differences in the mechanism involved in the acid transport which were dependent on the carbon source used for growth. 


\section{METHODS}

Micro-organism and growth conditions. Saccharomyces cerevisiae IGC 4072 was originally isolated from a sample of fermivin, an industrial wine yeast distributed by Rapidase. It was maintained on slants of glucose $(2 \%, \mathrm{w} / \mathrm{v})$, peptone $(1 \%, \mathrm{w} / \mathrm{v})$, yeast extract $(0.5 \%, \mathrm{w} / \mathrm{v})$ and agar $(2 \%, \mathrm{w} / \mathrm{v})$. The strain was grown at $25^{\circ} \mathrm{C}$, with mechanical shaking (150 r.p.m.), in 11 Erlenmeyer flasks containing $200 \mathrm{ml}$ liquid mineral medium with vitamins and oligoelements (van Uden, 1967), supplemented with the following carbon sources: glucose $(2 \%, \mathrm{w} / \mathrm{v})$, sucrose $(2 \%, w / v)$, fructose $(2 \%, w / v)$, galactose $(2 \%, w / v)$, maltose $(2 \%, \mathrm{w} / \mathrm{v})$, DL-lactic acid $(0.5 \%, \mathrm{v} / \mathrm{v} ; \mathrm{pH} 5.0)$, acetic acid $(0.5 \%, \mathrm{v} / \mathrm{v} ; \mathrm{pH} 5.0)$ or ethanol $(1 \%, \mathrm{v} / \mathrm{v})$.

Measurement of initial uptake rates. Cells were harvested in mid-exponential phase $\left(\mathrm{OD}_{640} 0 \cdot 5-0 \cdot 6\right)$, centrifuged, washed twice in ice-cold distilled water and resuspended in distilled water to a final biomass concentration of $25-35 \mathrm{mg}$ dry wt $\mathrm{ml}^{-1}$. Uptake rates of labelled monocarboxylic acids were estimated as described by Casal \& Leão (1995). Aqueous solutions of labelled acids $\left(3000-3300\right.$ d.p.m. nmol $\left.{ }^{-1}\right)$ were prepared at the desired concentration and $\mathrm{pH}$ values. Sampling times were 0,5 and $10 \mathrm{~s}$ for monocarboxylic-acid- or ethanol-grown cells and 0,30 and $60 \mathrm{~s}$ for glucose-grown cells, over which times the uptake of labelled acids was linear. Uptake was stopped by the addition of cold water. For nonspecific ${ }^{14} \mathrm{C}$ adsorption, labelled carboxylic acid was added after cold water at zero time. Inhibition by nonlabelled carboxylic acids was assayed by simultaneously adding the labelled and nonlabelled substrate.

The radioactively labelled acids utilized were: $\left[\mathrm{U}-{ }^{14} \mathrm{C}\right]$ acetic acid, sodium salt (CFA229; Amersham); DL-[U- $\left.{ }^{14} \mathrm{C}\right]$ lactic acid, sodium salt (CFB97; Amersham); and $\left[2-{ }^{14} \mathrm{C}\right]$ propionic acid, sodium salt (CFA88; Amersham).

Initial transport rates of proton uptake were measured as described by Casal \& Leão (1995).

Measurement of the intracellular volume. The intracellular volume was measured as previously described by De la Peña et al. (1981) and Rottenberg (1979). Using cells grown in medium with glucose, acetic acid or ethanol, the following values were obtained: $3.9 \pm 0.37,1.4 \pm 0.27$ and $1.3 \pm 0.21 \mu \mathrm{l}$ intracellular water $(\mathrm{mg} \text { yeast dry } \mathrm{wt})^{-1}$, respectively.

Measurement of acid accumulation. Preliminary experiments showed that propionic acid acted as a nonmetabolizable analogue of the monocarboxylate/proton symports in $S$. cerevisiae IGC 4072. Therefore this acid was used to study the accumulative capacity of these transport systems without interference from metabolism. Acetic-acid- or ethanol-grown cells $(25 \mu \mathrm{l})$ were added to $75 \mu \mathrm{l} 0 \cdot 1 \mathrm{M} \mathrm{KH}_{2} \mathrm{PO}_{4}$ buffer, adjusted to the desired $\mathrm{pH}$ value, and incubated at $25^{\circ} \mathrm{C}$ with magnetic stirring. The reaction was started by addition of $25 \mu \mathrm{l} 0.5 \mathrm{mM}$ $\left[{ }^{14} \mathrm{C}\right]$ propionic acid (3000-3300 d.p.m. nmol $\left.{ }^{-1}\right)$. At appropriate times, $10 \mu \mathrm{l}$ aliquots were taken from the reaction mixture into $5 \mathrm{ml}$ ice-cold water and filtered immediately through Whatman GF/C membranes. The filters were washed with $10 \mathrm{ml}$ ice-cold water and radioactivity was measured as described by Casal \& Leão (1995). In glucose-repressed cells, accumulation measurements were performed using the same methodology, but with labelled acetic acid (3000-3300 d.p.m. nmol ${ }^{-1}$ ).

For each type of cell, the intracellular concentration of total labelled acid was calculated using the respective intracellular volume value estimated as described in the previous section. The accumulation ratio, at each $\mathrm{pH}$ value, was estimated as the relationship between the intracellular and the extracellular acid concentration expressed as the anionic form of the acid. It was assumed that, under our experimental conditions, there was not a significant intracellular acidification induced by the acids; therefore the intracellular acid was totally dissociated.

Calculation of the concentrations of carboxylic acids as a function of $\mathbf{p H}$. Concentrations of the several ionization forms of carboxylic acids were calculated by the use of the HendersonHasselbalch equation with the following $\mathrm{p} K_{\mathrm{a}}$ values : propionic acid, $\mathrm{p} K_{\mathrm{a}}=4.88$; acetic acid, $\mathrm{p} K_{\mathrm{a}}=4.76$ (Dawson et al., 1989). Calculation of kinetic parameters for mediated transport systems. The experimental data-points from the labelled acid initial uptake experiments, as well as of the initial uptake rates of protons in the cell suspension, were analysed according to Furhman \& Völker (1992) by a computer-assisted nonlinear regression analysis using the GraphPAD computer program. By this method, best-fitting transport kinetics to the experimental initial uptake rate values were calculated and then values for kinetic parameters were obtained at a significance level $P<0.05$.

Estimation of glucose and acetic acid. Glucose and acetic acid were estimated using the glucose oxidase method Test-Combination kit (Boehringer Mannheim) and the acetic acid TestCombination kit (Boehringer Mannheim), respectively.

Reproducibility of the results. All experiments were repeated at least three times and the data reported here represent the mean values.

\section{RESULTS AND DISCUSSION}

\section{Acetic acid uptake systems and their regulation}

Cells of $S$. cerevisiae IGC 4072 grown in media with different carbon sources were analysed for elucidating the transport of acetic acid across the plasma membrane. Acetic acid uptake by cells grown in acetic acid medium $(0.5 \%, v / v)$ followed Michaelis-Menten kinetics (Fig. 1). The application of a computer-assisted nonlinear regression analysis to the experimental data (acid concentration $0.015-2.0 \mathrm{mM}$ ), as described in Methods, agreed with the presence of only one mediated transport system without contamination of a possible simple diffusion component of the undissociated acid (significance level $P<0.05)$. According to this methodology, at $\mathrm{pH}$ values of 5.0 and 6.0 , the $K_{\mathrm{m}}$ values were,

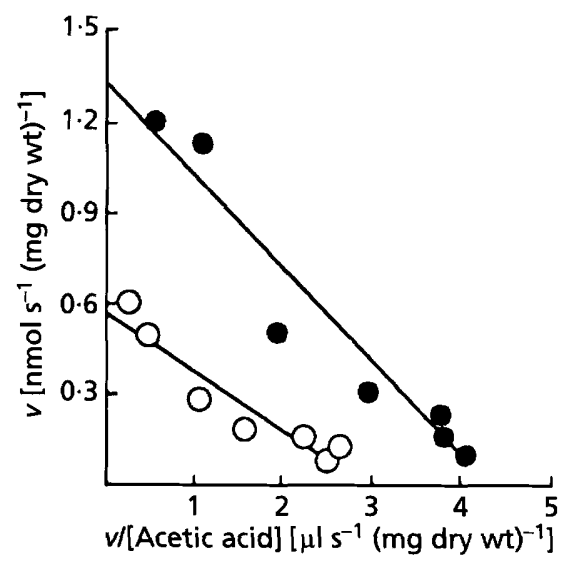

Fig. 1. Eadie-Hofstee plots of the initial uptake rates of $\left[{ }^{14} \mathrm{C}\right]$ acetic acid as a function of the acid concentration, at $\mathrm{pH}$ $5.0(0)$ and $6.0(0)$, by acetic-acid-grown cells of S. cerevisiae IGC 4072. 


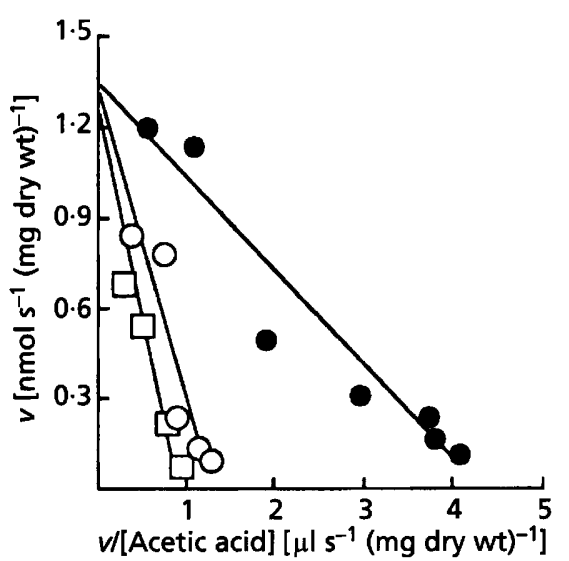

Fig. 2. Eadie-Hofstee plots of the initial uptake rates at $\mathrm{pH} 5.0$ of $\left[{ }^{14} \mathrm{C}\right]$ acetic acid by acetic-acid-grown cells of $S$. cerevisiae IGC 4072. Absence of other carboxylic acids; $\square$, presence of $5 \mathrm{mM}$ propionic acid; $O$, presence of $10 \mathrm{mM}$ formic acid.

respectively, $0.34 \pm 0.058$ and $0.21 \pm 0.039 \mathrm{mM}$ total acetic acid.

Propionic and formic acids, two substrates which were not metabolized by the strain under study when used as the sole source of carbon and energy in the culture medium, competed with acetic acid for transport at $\mathrm{pH}$ $5 \cdot 0$ (Fig. 2). Nevertheless, lactic and pyruvic acids, although being metabolizable by the yeast, had no significant inhibitory effect on the transport of labelled acetic acid. Furthermore, uptake rates of labelled lactic acid were negligible, no mediated transport activity for the acid being found. If transport of lactic acid occurred, it would proceed at a relatively insignificant rate.

Propionic acid, which, as illustrated above, behaved as a nonmetabolizable analogue of acetic acid, was accumulated and transport was strongly sensitive to carbonyl cyanide $m$-chlorophenylhydrazone (CCCP). This protonionophore, at $\mathrm{pH} 5 \cdot 0$, induced a significantly rapid efflux of the free accumulated acid (Fig. 3a). The presence of proton uptake associated with the acid uptake was also tested. Initial transport rates were measured by monitoring proton uptake by cell suspensions in weak buffer, after propionic acid addition at $\mathrm{pH} 4 \cdot 0$ and $5 \cdot 0$, as described in Methods. The addition of propionic acid to cells produced significant extracellular alkalization, the Eadie-Hofstee plots of initial rates of proton disappearance from the external buffer being linear over the experimental range of $0.01-0.5 \mathrm{mM}$ (data not shown). At higher acid concentrations, it was not possible to estimate proton uptake rates, probably due to the buffering capacity of the acid itself. Similar results were obtained with acetic and formic acids. These results, although consistent with the hypothesis of a proton symport for the anionic form of the acid (for a review, see Stein, 1986), do not constitute definite proof. As can easily be demonstrated, facilitated diffusion of undissociated acid would lead to similar proton movements due, not to the influx of protons into the cells, but to the re-establishment of the acid-base equilibrium disturbed by the influx into cells of undissociated acid. Similarly, the observed accumulation of propionic acid would also occur at external $\mathrm{pH}$ values lower than the intracellular $\mathrm{pH}$ if undissociated acid was the transported form, though for different reasons than in the transport of the anionic form by a proton symport. In the former case, the anions formed at the higher intracellular $\mathrm{pH}$ are trapped and accumulate as a function of $\Delta \mathrm{pH}$, whereas in the latter case $\Delta \mathrm{pH}$ functions as a thermodynamic driving force for proton-associated anion transport. The rapid efflux of accumulated radioactive acid that was observed after the addition of CCCP, which short-circuits the transmembrane proton motive force, strongly indicates a proton symport mechanism involved in the anion transport. If CCCP eventually decreases the intracellular $\mathrm{pH}$ and thus induces efflux of propionic acid in the case of a facilitated diffusion system, the effect would be much more delayed, if occurring at all, due to the great buffering capacity of the cytoplasm. Moreover, and consistent with these observations, when cells were pre-incubated with $50 \mu \mathrm{M}$ CCCP for $2 \mathrm{~min}$, effective inhibition of initial uptake rates of labelled propionic acid, at different $\mathrm{pH}$ values, was observed $(74 \%$ inhibition at $\mathrm{pH} 4.0 ; 80 \%$ inhibition at $\mathrm{pH} 5.0$ ). If undissociated acid was the transported form, there is no obvious reason to expect such strong inhibitory effects. All of this experimental evidence is consistent with the involvement of the transmembrane proton motive force in the transport and accumulation of the acid. This therefore favours the presence of a proton symport for the anionic form, rather than a facilitated diffusion of the undissociated acid. Addition of cold propionic and acetic acids at maximal accumulation time, corresponding to $\mathrm{pH} 5 \cdot 0$, caused a rapid efflux of the labelled compound (Fig. 3a), reinforcing the theory that these acids shared the same carrier. Lactic or pyruvic acid did not induce a rapid and significant counterflow and neither of them produced an extracellular alkalization, which strengthens the theory that these acids were not recognized as substrates for the acetate carrier.

The propionic acid accumulation ratio, expressed as [propionate $]_{\text {in }} /[\text { propionate }]_{\text {out }}$, was a linear function of the extracellulat $\mathrm{pH}$ (Fig. 3b), suggesting that the proton symport is electroneutral and consequently associated with a proton/anion stoichiometry of $1: 1$. This ratio was confirmed by the application of a theoretical model previously developed to analyse proton movements associated with the uptake of weak carboxylic acids (Cássio et al., 1993). Thus, the system should not be sensitive to ionophores that typically collapse the transmembrane electric potential $(\Delta \psi)$, such as tetraphenylphosphonium ions $\left(\mathrm{TPP}^{+}\right)$. Indeed, when initial uptake rates of labelled propionic acid, at $\mathrm{pH} 4.0$ and 5.0 , were measured after incubation for 2 min with $20 \mathrm{mM} \mathrm{TPP}^{+}$, no significant inhibition was observed $(0 \%$ inhibition at $\mathrm{pH} 4 \cdot 0 ; 22.7 \%$ inhibition at $\mathrm{pH} 5 \cdot 0)$. Taking the results together, it can be concluded that in acetic-acid-grown cells, acetate, propionate and formate could cross the plasma membrane through a common electroneutral monocarboxylate/proton symport, essentially dependent on the transmembrane $\Delta \mathrm{pH}$. Other monocarboxylic acids 

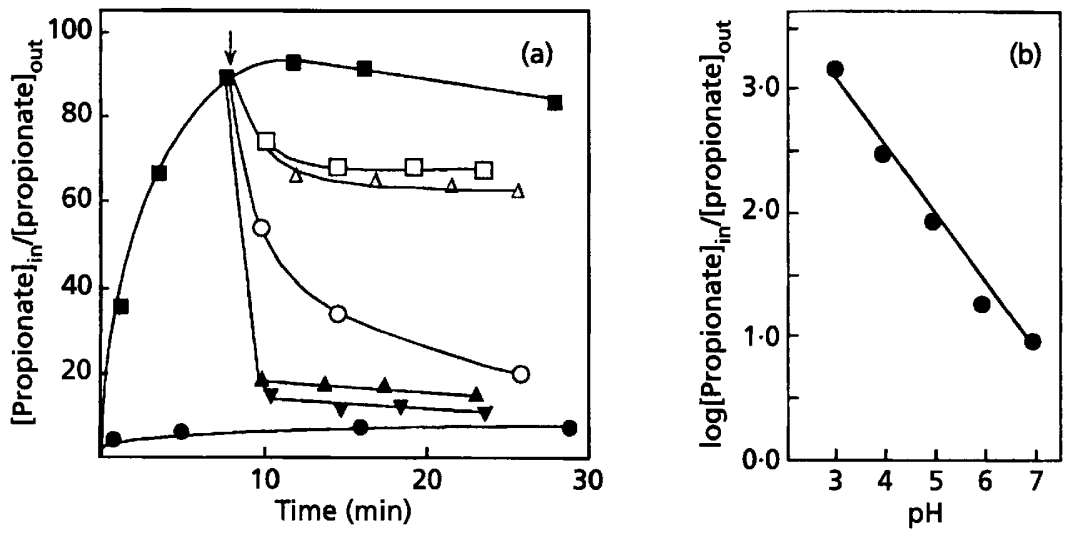

Fig. 3. (a) Accumulation of $\left[{ }^{14} \mathrm{C}\right]$ propionic acid at pH $5.0(\square)$ by acetic-acid-grown cells of $S$. cerevisiae IGC 4072. The initia extracellular concentration of total propionic acid was $3.78 \mathrm{mM}$. At the time indicated by the arrow, additions were: $\boldsymbol{A}$, cold acetic acid to a final concentration of $0.2 \mathrm{M} ; \nabla$, cold propionic acid to a final concentration of $0.2 \mathrm{M} ; \triangle$, cold pyruvic acid to a final concentration of $0.2 \mathrm{M} ; \square$, cold lactic acid to a final concentration of $0.2 \mathrm{M}$; 0, CCCP to a final concentration of $0.1 \mathrm{mM}$. - $0.1 \mathrm{mM}$ CCCP added to the reaction mixture before addition of labelled propionic acid. (b) Dependence of the accumulation ratio of $\left[{ }^{14} \mathrm{C}\right]$ propionic acid in acetic-acid-grown cells of $S$. cerevisiae IGC 4072 on extracellular $\mathrm{pH}$.

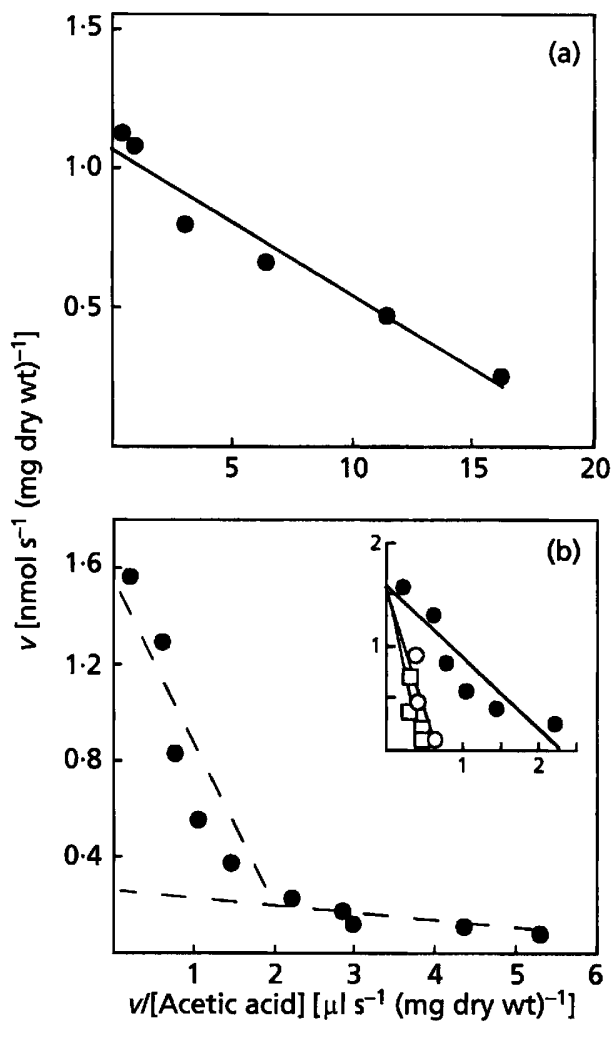

Fig. 4. Eadie-Hofstee plots of the initial uptake rates at $\mathrm{pH} 5 \cdot 0$ of labelled acetic acid by S. cerevisiae IGC 4072. (a) Ethanolgrown cells. (b) Lactic-acid-grown cells; the insert represents the low affinity component measured in the absence of other carboxylic acids (O), in the presence of $5 \mathrm{mM}$ propionic acid $(\square)$ or in the presence of $10 \mathrm{mM}$ formic acid (O).

such as lactic and pyruvic acids were not recognized by the carrier and, at least in the case of lactic acid, the membrane was shown to be apparently impermeable to the anion.

Cells grown in ethanol medium displayed a behaviour very close to that described above for acetic-acid-grown cells. They transported acetic acid by a mediated transport system (Fig. 4a) with the following kinetic parameters at
$\mathrm{pH} 5 \cdot 0: K_{\mathrm{m}}, 0.05 \pm 0.065 \mathrm{mM}$ total acetic acid and $V_{\max }$, $1.1 \pm 0.06 \mathrm{nmol} \mathrm{s}^{-1}$ (mg dry wt cells) $)^{-1}$. The carrier was shared by propionate and formate but not by lactic and pyruvic acids, and exhibited a behaviour which in all likelihood was a proton/symport for the anionic form of the acids (not shown).

Lactic-acid-grown cells were also tested for the presence of the above acetate/proton symport. The Eadie-Hofstee plot of initial velocities of labelled acetic acid uptake at $\mathrm{pH}$ 5.0 , at concentrations up to $6 \mathrm{mM}$, was biphasic, pointing to the presence of two distinct transport modes for acetic acid (Fig. 4b). Moreover, the application of the same computer-assisted nonlinear regression analysis referred to above for acetic-acid-grown cells indicated that the experimental data were best fitted (significance level $P<0.05)$ by two Michaelis-Menten kinetic terms. The following kinetic parameters were calculated at $\mathrm{pH} 5 \cdot 0$ : for the low-affinity system, $K_{\mathrm{m}}=1.52 \pm 0.319$ $\mathrm{mM}$ total acetic acid and $V_{\max }=1 \cdot 86 \pm 0.177 \mathrm{nmol} \mathrm{s}^{-1}$ (mg dry wt cells) ${ }^{-1}$; for the high-affinity system, $K_{\mathrm{m}}=0.02 \pm 0.007 \mathrm{mM}$ total acetic acid and $V_{\max }=$ $0.21 \pm 0.026 \mathrm{nmol} \mathrm{s}^{-1}(\mathrm{mg} \text { dry wt cells })^{-1}$. It has already been reported that in lactic-acid-grown cells, acetate was the substrate for the same monocarboxylate/proton symport as lactate, propionate and pyruvate (Cássio $e t$ al., 1987). According to our results, the substrate specificity pattern exhibited by the high-affinity component of the acetic acid transport was essentially identical to the monocarboxylate/proton symport described in lacticacid-grown cells by Cássio et al. (1987). Estimates of initial uptake rates of labelled acetic acid in the presence of several monocarboxylic acids showed that lactic, propionic and pyruvic acids were competitive inhibitors for the high-affinity transport system, suggesting that they shared a common carrier; formic acid was not a competitive inhibitor for this high-affinity acetic acid transport system (results not shown). In turn, the low-affinity component behaved as the acetate/proton symport observed in acetic-acid-grown cells. Inhibition uptake studies in the low-affinity range indicated that acetic, propionic and formic, but not lactic and pyruvic acids, were competitive inhibitors for the system (Fig. 4b).

In glucose-, fructose-, sucrose-, maltose- or galactose- 


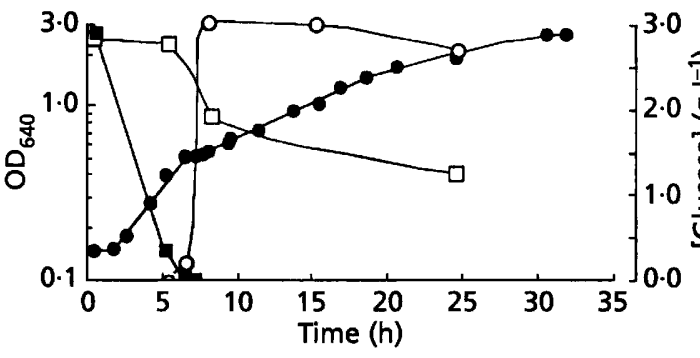

grown cells, a different behaviour was found. These cells did not display any activity of the two monocarboxylate/ proton symports in the $\mathrm{pH}$ range $3 \cdot 0-6.0$. In medium with a mixture of glucose and acetic acid ( $\mathrm{pH} 5 \cdot 0)$, growth was diauxic, and activity of the acetate-propionate-formate carrier, as well as acetic acid assimilation, became measurable only after glucose had been consumed (Fig. 5). If acetic acid was replaced by ethanol in the culture medium, again the acetate carrier could be detectable only after glucose was exhausted (not shown). Activity of the lactate/proton symport present in lactic-acid-grown cells was not found under these two growth conditions.

\section{Simple diffusion of the undissociated acid}

In cells grown under glucose repression and lacking activity of the two monocarboxylate carriers, the acids were able to cross the plasma membrane by simple diffusion. Plots of initial uptake rates of labelled acetic acid, as a function of the concentration of the undissociated acid in the $\mathrm{pH}$ range 3.5-6.0, were linear (Fig. 6a). Similar results had also been found for the transport of lactic acid in glucose-grown cells of the same strain (Cássio et al., 1987). The values of diffusion constants were calculated from the slopes of the plots, and comparison of the absolute values obtained for the diffusion constants for both acids indicated that the permeability of the membrane for the undissociated acetic acid is much higher than for lactic acid. Furthermore, the diffusion constants for acetic acid appear not to be so significantly affected by the extracellular $\mathrm{pH}$, increasing only about threefold between $\mathrm{pH} 3.5$ and 6.0 , while over the same $\mathrm{pH}$ range, the diffusion constants for the undissociated lactic acid increased about 50-fold (Fig. 6b).

Metabolism of acetic and lactic acids was subject to glucose repression. Thus, in glucose-grown cells, if no transport system is present for the efflux of the anion, once inside the cell the acid dissociates and can accumulate as a function of the $\Delta \mathrm{pH}$. In fact, this appears to be the case. Under such growth conditions, transport of labelled acetic acid was accumulative (Fig. 6b), the accumulation ratio being a function of the extracellular $\mathrm{pH}$. Furthermore, a negligible and very delayed efflux was induced by CCCP when added at the steady state (not shown), which strongly reinforces the theory that the observed accumulation was not due to the involvement of the proton motive driving force (for a detailed discussion, see Côrte-Real et al., 1989).
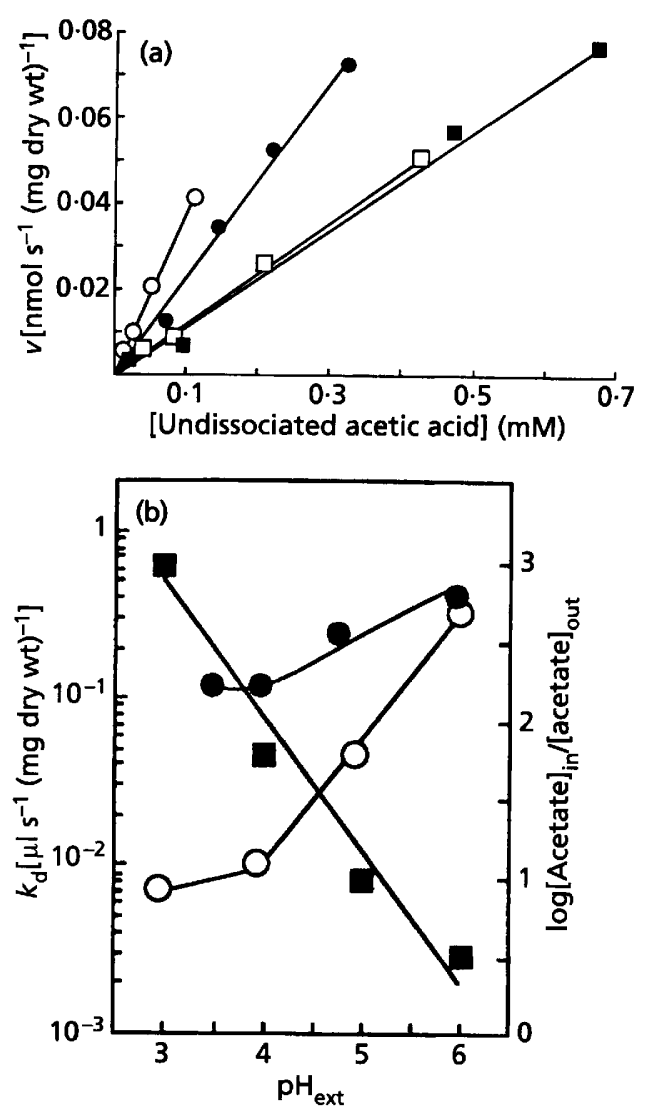

Fig. 6. Uptake and accumulation of labelled acetic acid by glucose-repressed cells of $S$. cerevisiae IGC 4072. (a) Initial uptake rates of labelled acetic acid as a function of the concentration of undissociated acid at various extracellular $\mathrm{pH}$ values: $3.5(\square), 4.0(\square), 4.8(0)$ and $6.0(O)$. The straight lines obtained had slopes of $0.117 \pm 0.0073(r=0.99), 0.117 \pm 0.0044$ $(r=0.99), 0.238 \pm 0.0153(r=0.99)$ and $0.377 \pm 0.0066(r=0.99)$, corresponding to the diffusion constants of labelled acetic acid at $\mathrm{pH} 3.5,4.0,4.8$ and 6.0 , respectively. (b) Extracellular $\mathrm{pH}$ dependence of the diffusion constants (O) and of the accumulation ratio of labelled acetic acid $(\square)$. In this figure, the diffusion constants for labelled lactic acid previously reported by Cássio et al. (1987) are also represented (O).

In conclusion, our results show that $S$. cerevisiae IGC 4072 exhibited significant differences in the mechanism involved in the transport of acetic acid and other monocarboxylic acids, depending on the growth carbon source. If acetic acid or ethanol was used in the culture medium as 
the only carbon and energy source, the cells were able to transport acetic, propionic and formic acids by the same monocarboxylate/proton symport and appeared to be impermeable to lactic and pyruvic acids. If growth occurred in lactic acid medium, two distinct proton symports coexisted for the transport of monocarboxylates. One corresponded to the lactate/proton symport previously described by Cássio et al. (1987) and the other, with lower affinity and a more restricted substrate specificity, to the acetate/proton symport described in the present paper. Both carriers were subject to glucose repression, but while the high-affinity system was dependent on the presence of an external inducer like lactic acid, the low-affinity system had no such requirement, being present in acetic-acid-, lactic-acid- or ethanolgrown cells. Two distinct monocarboxylate/proton symports repressed by glucose with substrate specificities identical to those described here in $S$. cerevisiae have also been previously reported in the yeast $T$. delbrueckii (Casal \& Leão, 1995). However, in this yeast species, unlike $S$. cerevisiae, both systems were dependent on specific external inducers. Finally, in glucose-repressed cells of $S$. cerevisiae, the permeability of the membrane to acetic acid was found to be much higher than to lactic acid. Thus, when the yeast is present in media with mixtures of glucose and acetic acid, at low $\mathrm{pH}$, the acid accumulates quickly inside the cell, which could account for the negative effects of the acid on the yeast metabolic activity. Further studies are presently under development in order to elucidate this possible correlation between the type of mechanism involved in the transport of acetic acid and its toxic effects in $S$. cerevisiae.

\section{ACKNOWLEDGEMENTS}

This study was supported by a research grant (contract CNA4/GLAXO/29082) from GLAXO Farmacêutica, L ${ }^{\text {da }}$, Portugal.

\section{REFERENCES}

Barnett, J. A., Payne, R. W. \& Yarrow, D. (1990). Yeasts: Characteristics and Identification, 2nd edn. Cambridge: Cambridge University Press.

Casal, M. \& Leão, C. (1995). Utilization of short-chain monocarboxylic acids by the yeast Torulaspora delbrueckii: specificity of the transport systems and their regulation. Biocbim Biophys Acta 1267, 122-130.
Casal, M., Blázquez, M., Gamo, F. J., Gancedo, C. \& Leão, C. (1995). Lack of lactate-proton symport activity in pck1 mutants of Saccharomyces cerevisiae. FEMS Microbiol Lett 128, 279-282.

Cássio, F., Leão, C. \& van Uden, N. (1987). Transport of lactate and other short-chain monocarboxylates in the yeast Saccharomyces cerevisiae. Appl Environ Microbiol 53, 509-513.

Cássio, F., Côrte-Real, M. \& Leão, C. (1993). Quantitative analysis of proton movements associated with the uptake of weak-carboxylic acids. The yeast Candida utilis as a model. Biochim Biophys Acta 1153, 59-66.

Côrte-Real, M., Leão, C. \& van Uden, N. (1989). Transport of $\mathrm{L}(-)$ malic acid and other dicarboxylic acids in the yeast Candida sphaerica. Appl Microbiol Biotecbnol 31, 551-555.

Dawson, R. M. C., Elliot, D. C., William, H. E. \& Jones, K. M. (1989). Data for Biochemical Research, 3rd edn. Oxford: Clarendon Press.

De la Peña, P., Barros, F., Gascon, S., Lazo, P. S. \& Ramos, S. (1981). Effect of yeast killer toxin on sensitive cells of Saccharomyces cerevisiae. J Biol Chem 256, 10420-10425.

Eddy, A. A. \& Hopkins, P. G. (1985). The putative electrogenic nitrate-proton symport of the yeast Candida utilis: comparison with the systems absorbing glucose or lactate. Biochem J 231, 291-297.

Fonseca, A., Spencer-Martins, I. \& van Uden, N. (1991). Transport of lactic acid in Kluyveromyces marxianus: evidence for a monocarboxylate uniport. Yeast 7, 775-780.

Furhman, G. F. \& Völker, B. (1992). Regulation of glucose transport in Saccharomyces cerevisiae. J Biotechnol 27, 1-15.

Gancedo, C. \& Serrano, R. (1989). Energy yielding metabolism. In The Yeasts, vol. 3, pp. 205-251. Edited by A. H. Rose \& J.S. Harrison. London \& San Diego: Academic Press.

Leão, C. \& van Uden, N. (1986). Transport of lactate and other monocarboxylates in the yeast Candida utilis. Appl Microbiol Biotechnol 23, 389-393.

Rottenberg, H. (1979). The measurement of membrane potential and $\mathrm{pH}$ in cells, organelles and vesicles. Methods Envymol 55, 547-569.

Stein, W. D. (1986). Transport and Diffusion Across Cell Membranes. London \& San Diego: Academic Press.

van Uden, N. (1967). Transport-limited fermentation and growth of Sacharomyces cerevisiae and its competitive inhibition. Arch Microbiol 58, 155-168.

Received 9 October 1995; revised 13 January 1996; accepted 16 January 1996. 